\title{
Modernization Principles of the Dual Education System Development in Hotel and Restaurant Business
}

\author{
Andrii Holod, Andrii Shevchuk, Oryslava Korkuna
}

\begin{abstract}
The paper deals with the methodological principles of the dual education development in the hotel and restaurant business considering the modernization paradigm. The preconditions for the formation of dual education systems in different countries suggest that such an approach should be more appropriately applied to practically oriented specialties. Analysis of the advantages and disadvantages of existing dual education systems offers an opportunity to suggest ways to modernize them in the conditions of the information society development. The paper proposes a system of principles (general and specific) on which the cooperation of higher education institutions and hotel and restaurant business should be based. The stages and methodological approaches to the analysis of hotel and restaurant business modernization processes in the context of the formation of a dual education system are substantiated.

Keywords : Concept. Cooperative Education. Foundations. Hospitality Industry. System.
\end{abstract}

\section{INTRODUCTION}

The issues that determine the directions of service industries development become especially relevant in the conditions when the social systems are moving to new technological orders and knowledge economy. Such directions can be grounded in with the application of innovation development concept. However, innovative development prioritizing innovation management at different hierarchical levels of economic systems cannot simultaneously change the structure and directions of such systems development.

The process of innovation development is continuous and often comprises only the modern types of economic activity, somewhat exaggerating their promising and economic efficiency. At the same time, traditional approaches applied in a number of industries also need to be reviewed and refined. The issues arising in this context go beyond the traditional understanding of innovation and require new approaches which in the hospitality industry should be interpreted within the framework of modernization concept, in particular, based on the principles of a system approach.

In previous studies (Holod 2017), in which the modernization concept of regional tourism systems was substantiated, the educational subsystem as an integral component of socially oriented tourism development was singled out in their structure.

Revised Manuscript Received on November 15, 2019

Andrii Holod, Oryslava Korkuna, Department of Hotel and Restaurant Business, Lviv State University of Physical Culture named after Ivan Boberskii, Kostyushka Str., 11, Lviv, Ukraine aholod2012@gmail.com grafskayaorislava@gmail.com

Andrii Shevchuk Department of Economic Cybernetics and Marketing, Cherkasy State Technological University, Shevchenko Boulevard, 460, Cherkasy, Ukraine , Eavshevc@gmail.com
T. Schultz (1960) identified education as one of the forms of human capital, which may be a source of profits, not only of material nature. Followers of this concept (Sen 1990) emphasized that the formation of human capital should be one of the priorities of the state policy in "human development" and can be realized primarily through the education system modernization.

In the 1960s, the filter theory, which substantiated the priority of the educational factor for effective recruitment, became widespread among scientists. Proponents of this theory put forward not productive, but a selective (informational) function of education, which implies a direct relationship between the level of education and the qualifications of a worker (Arrow 1973).

At the same time, the filter theory has undergone considerable criticism (Layard, Psacharopoulos 1974) based on the fact that the relationship between education and labor productivity relates only to certain occupations and does not indicate the existence of general tendencies.

The contradictions in the relationship between education and the specifics of employment arose not only in the scientific community but also in the practice of doing business. A student who has graduated from high school, but does not have experience in the specialty, gave way to the labor market for people without professional education, but with some work experience.

The role of education as a factor in vocational training has changed even more with the formation of an information society. Indeed, according to M. Castells (1997), information becomes a system-forming factor in the development of society, the main characteristic of which is the network logic of social structure organization at the global, regional, and local levels.

There was a need to develop new approaches that would enable effective cooperation between educational institutions and business. In a number of countries, cooperative and dual education systems have been developed and implemented to ensure and harmonize the interests of educational institutions, students and employers.

The most effective system is dual education in Germany, which arose through the transfer of the traditional vocational training system in higher education (Göhringer 2002). Similar systems have developed and operate in Austria, Switzerland, the United States, and recently also in the newly industrialized countries of Asia and Latin America.

In spite of obvious advantages, the introduction of dual education has been subject to some criticism from the adherents of traditional higher education. It was emphasized that the methodological foundations of dual (cooperative) education are vague and underdeveloped (Van der Vorm 1988). 
The combination of learning with work undermines the theoretical training and intellectual development of students. At the same time, employees of enterprises responsible for the professional training of students do not adequately perform their functions as teachers, focusing on organizational aspects (Eames C, Cates C 2011).

However, despite some controversy, most researchers agree that dual education has obvious advantages and prospects in certain industries and related practically oriented educational specialties (including hotel and restaurant business).

\section{OBJECTIVES}

The purpose of the paper is to develop methodological principles for the dual education development in hotel and restaurant business, taking into account the modernization paradigm of regional development; to justify the system of principles on which the cooperation of higher education institutions and business in this industry should be based.

\section{METHODOLOGY}

The literary sources analysis method is used to work out the scientific approaches of researching the problems of dual education development at the global and regional context. The use of synthetic methods made it possible to isolate and formulate the principles of hotel and restaurant business modernization.

\section{RESULTS AND DISCUSSION}

Modernization is interpreted by researchers as the institutional dynamics of a modern economic system with a view to developing its new qualities through the attraction of traditional and new specializations using knowledge, ethnocultural features, socio-humanitarian and naturalresource opportunities in accordance with public needs and global standards. Thus, modernization provides a sustainable reproduction process in the economic system under the influence of innovative factors (Holod 2017).

The main objectives of the education modernization are to ensure its high quality, to build an effective national educational system and regional educational systems with a real economy and management that meets the needs of the modern society and regional socio-economic development.

Modernization of the regional education system should include its full and multidimensional progressive changes. Accordingly, the following priority directions of education system modernization (Shevchuk 2013) can be distinguished:

- Modernization of the education management system;

- Ensuring access to education for people with disabilities and special needs;

- Compliance with high-quality standards of education, training teaching staff, especially in the regions;

- Support of high-quality private education, development of educational management and educational innovations, support of new educational projects and services, development of a favorable regulatory framework for the investments in educational services.

The main steps in modernizing the learning process in higher education should be:

- Science development at universities to improve their global ranking and competitiveness;
- Support of leading higher education institutions in order to form a positive image of national education;

- Development of a system for conducting an independent assessment of higher education institutions, their programs; a single rating that takes into account the quality of personnel, compliance with international standards;

- Development of the professional college's system as the first link of multi-level higher education; support of private institutions that are able to respond more quickly to market challenges and generate educational innovations.

In the process of forming a dual education system, modernization should include all its elements, the key of which are institutions of higher education and business. Modernization of the hotel and restaurant business as a subsystem of the hospitality industry and the education system of the region (state) should be based on an interconnected set of principles - general and specific.

\section{General principles}

1. Scientificity. Modernization should be based on the theoretical, methodological and applied approaches developed in the framework of special studies on hospitality industry management. It is possible to substantiate the mechanisms of regulating the development of hotel and restaurant business in the region (state) only if the cooperation between educational, scientific institutions and authorities is established.

2. Complexity. Modernization processes should include all components of economic systems, and also take into account the overall impact of environmental factors.

3. Balance. It provides the optimal combination of various modernization components - institutional, innovative, and securable. Not only objectives but also specific tasks of modernization that can be resolved within the competence of local governments and individual educational institutions should be balanced.

4. Sustainability. Taking into account the principles of sustainable development in the process of modernizing the hotel and restaurant business. Improving the structural and functional characteristics of the hospitality industry at the present stage should not have a destructive effect on the functioning of other components of the economy.

5. Transparency. Ensuring transparency of decisions on modernization changes in the hospitality industry. It may take place through public discussion of innovative projects and other forms of involvement of civil society institutions, full coverage of planned events in mass media.

6. Motivational. The directions of modernization should be conditioned by well-defined and objective needs that arise in the process of hospitality industry development. Any administrative decision on the improvement of doing hotel and restaurant business must be well-reasoned and scientifically grounded.

7. Synergism. Use of a synergistic approach that treats the investigated processes like the growth of the corresponding system's instability. Provides the presence of information, innovation, and social modernization "triggers". Determines the multivariate development of the hospitality industry and the possibility of both rapid qualitative changes in its parameters, as well as the activation of destructive processes associated with 
increasing instability of the system.

8. Dynamism. Taking into account the trends of hospitality industry development in a region (state). Analysis of the dynamics and revealed trends in the development of hotel and restaurant business gives an opportunity to assess the modernization potential of the dual educational systems formation.

9. Adaptability. During the substantiation, development, and implementation of modernizing influence on the formation of dual educational systems in the hotel and restaurant business, instability of the environmental conditions must be taken into account. The necessary component of managing such processes is minimizing the risks associated with both the threats to the environment that require confrontation (defense) and the challenges that the system must respond to, increasing its sustainability and development potential.

10. Efficiency. Modernization changes must be effective, that is, to anticipate the achievement of the expected goals. The degree of dual educational system modernization efficiency in the hotel and restaurant business is thus the main criterion for the feasibility of introducing it into the practice.

\section{SPECIFIC PRINCIPLES}

1. Continuity. The phenomena and processes underlying the functioning of hospitality industry are continuous and inertial. The established connections in combination with the internal stability of the system determine the low efficiency of both transformation and modernization processes in the short term. At the same time, the continuity of the system guarantees its resistance to external threats and risks of instability, which is a positive feature from the standpoint of a security approach.

2. Subsidiarity. Using delegated powers to regulate modernization processes at the regional and local levels, if the effectiveness of such measures is higher than at the national level. The specificity of dual education in the hotel and restaurant business, which is developing on the basis of spatially localized objects (educational institutions and enterprises), determines the special relevance of the subsidiary approach.

3. Incongruity. During the dual education organization, new relationships and spatial formations are formed which leads to unequal initial status and structure of the system and the resulting changes after modernization. The incongruity nature of modernization is especially characteristic for the hospitality industry since its development is based on tourist flows that have not only system-formative but also creative value.

4. Fluctuation. Under conditions of instability, the system of dual education is subjected to a number of threats that have a stochastic character and cause nonlinear changes in its states. Substantiating the strategic directions of modernization of such a system, it is necessary to take into account not only existing trends but also the forecast of probable system state fluctuations.

5. Stochasticity. The influence of the factors that determine the functioning parameters of educational systems is probabilistic. Minimizing the risks of activating destructive processes is thus one of the key tasks of the modernization strategy for the development of the hospitality industry in a region.

6. Consequentialism. Sequence and stage-by-stage application of methods and tools for dual education system modernization in hotel and restaurant business with the purpose of full realization of the tasks connected with guaranteeing a qualitatively new development of such a system. This principle should be fundamental in the process of strategic management under conditions of instability and reflected in the sequence of goals and objectives of the developed strategy.

7. Selectivity. The need to select the target components of the educational system for the purpose of applying modernization tools. Identification of the most suitable for modernization subsystem should be carried out on the basis of criteria analysis of factors and modernization potential assessment.

8. Ontology. During the substantiation of hospitality industry modernization paradigm, the fundamental principles of ontology as a doctrine of being, its fields and forms must be taken into account. The complex social and space-information problems of the hotel and restaurant business should be analyzed in the context of two interacting entities - objective and subjective.

9. Axiology. The modernization paradigm of the hospitality industry should take into account the valuable nature of education as a social phenomenon. The complex combination of social and personal values with external socio-cultural factors, which inevitably influences the target system, necessitates an analysis of the axiological preconditions of modernization policy, particularly in the context of globalization.

10. Sociohumanization. Analyzing the peculiarities of the tourism systems functioning at various hierarchical levels, it is necessary to take into account the sociopsychological and humanitarian principles. The hotel and restaurant business as a component of the service sector must, first of all, take into account the human needs and the peculiarities of human capital development in a social system. Modernization on the basis of sociohumanization should also provide for the priority of social regulation.

The system of described principles is based on the methods, factors, tools, and models of hotel and restaurant business modernization in the context of the formation of a dual education system, the spatial-temporal organization of which enables to distinguish specific tasks, which are united in the following stages:

1) Substantiation of the modernization conceptual foundations;

2) Evaluation of resource opportunities for activating the functioning of educational systems;

3) Directions of personnel support and establishment of effective municipal management;

4) Formation of investment attractiveness for the infrastructure capacity modernization;

5) Harmonization of the educational system influence on a qualitatively new trajectory of regional space development.

The main methodological approaches that can be used to analyze hotel and restaurant business modernization processes in the context of dual education system formation are systematic, structural, network, process, large scale, situational,

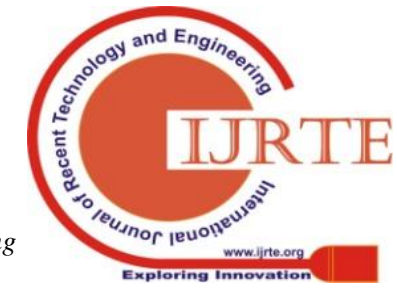


functional, complex, integration, and differentiation. The mentioned approaches allow solving complex problems of methodological substantiation and institutional provision of measures aimed at modernizing educational systems at different levels.

\section{CONCLUSION}

Consequently, the modern education system can not be developed separately from society and must respond to the challenges of the information age. Proven by the time and experience of individual countries, the concept of dual education also needs to be modernized. Such modernization should be understood not only the introduction of new approaches and methods in the organization of cooperative learning but also the development of a methodological basis for reforming the system of dual education in new conditions.

The proposed general and specific principles of hotel and restaurant business modernization in the context of dual education system formation provide an opportunity to substantiate a holistic concept that can be implemented at both the national and regional levels. The specificity of the hotel and restaurant business as a component of the hospitality industry determines its special role in the modern socially oriented and globalized economy. That is why students studying in this specialty require a thorough theoretical education (socio-humanitarian and economic cycle) as well as practical training.

\section{RECOMMENDATIONS}

The results of the research can be used as a methodological basis for the formation of the concepts of dual education development in general and in the hotel and restaurant business in particular. Such concepts are needed both in countries where the system of dual education has long been functioning and in others (including Ukraine), where the strategic and regulatory approaches of education and business cooperation in the process of training are only formed.

The proposed modernization paradigm, formed by a system of principles and approaches, can be the basis for further research in the field of economics and education management, strategic management, and a wide range of interdisciplinary studies of the hospitality industry.

\section{REFERENCES}

1. Arrow KJ 1973. Higher education as a filter. Journal of Public Economics, 2(3). 193-216.

2. Castells M 1997. The End of the Millennium, The Information Age: Economy, Society and Culture. Cambridge, MA; Oxford, UK: Blackwell.

3. Eames C, Cates C 2011. Theories of learning in cooperative and work-integrated education. International handbook for cooperative and work-integrated education: International perspectives of theory, research and practice. 2. 41-52.

4. Fässler J 2018. Implementing the dual education system: the success, the challenges and the future. From <https://www.alpla.com/en/blog/2018/03/implementing-dualeducation-system-success-challenges-and-future> (Retrieved on 1 July 2019).

5. Göhringer A 2002. University of Cooperative Education - Karlsruhe: The Dual System of Higher Education in Germany. Asia-Pacific Journal of Cooperative Education, 3(2). 53-58.

6. Holod A 2017. Bezpeka rehional'nykh turystychnykh system: teoriya, metodolohiya ta problemy harantuvannya [Safety and Security of Regional Tourism Systems: Theory, Methodology, and Guarantee Problems]. Lviv: LSUPC.
7. Layard R, Psacharopoulos G 1974. The Screening Hypothesis and the Returns to Education. Journal of Political Economy, 82. 985-998.

8. Schultz TW 1960. Capital Formation by Education. Journal of Political Economy, 6. 571-583.

9. Sen A 1990. Development as Capability Expansion. Human Development and the International Development Strategy for the 1990s. London: Macmillan, pp. 41-58.

10. Shevchuk A 2013. Rehional'ni osvitni systemy: teoriya, metodolohiya, praktyka innovatsiynoho rozvytku [Regional Educational Systems: Theory, Methodology, Practice of Innovative Development]. Lviv: Institute for Regional Studies of the NAS of Ukraine.

11. Van der Vorm PT 1988. Response to the Preliminary Report of the Ad Hoc Committee on Cooperative Education. Journal of Cooperative Education, 24(2-3). 120-124.

\section{AUTHORS PROFILE}

Andrii Holod, Oryslava Korkuna, Department of Hotel and Restaurant Business, Lviv State University of Physical Culture named after Ivan Boberskii, Kostyushka Str., 11, Lviv, Ukraine aholod2012@gmail.com grafskayaorislava@gmail.com

Andrii Shevchuk Department of Economic Cybernetics and Marketing, Cherkasy State Technological University, Shevchenko Boulevard, 460, Cherkasy, Ukraine , Eavshevc@gmail.com 